\title{
Implementasi metode Global Trigger Tool IHI (Institute for Healthcare Improvement) untuk identifikasi kejadian tak diinginkan (KTD) di pelayanan kebidanan RSUD Pariaman Provinsi Sumatera Barat
}

\author{
Aladin $^{1}$, Tjahjono Kuntjoro², Trisasi Lestari² \\ 1. Fakultas Kedokteran Universitas Andalas; 2 Fakultas Kedokteran Universitas Gadjah Mada
}

Korespondensi: Aladin, email: iko nyo2002@yahoo.com

\begin{abstract}
Abstrak
Kesalahan yang terjadi dalam proses perawatan medis berpotensi dan dapat menyebabkan cedera pada pasien yang merupakan peristiwa buruk. Institute for Healthcare Improved Global Trigger Tool adalah salah satu metode analisis retrospektif yang menggunakan "pencetus" atau "pemicu" untuk mendeteksi kemungkinan peristiwa buruk. Pentingnya rumah sakit dalam memberikan layanan dan dalam rangka meningkatkan perawatan kebidanan, maka IHI dapat menjadi alternatif jawaban masalah yang ada. Tujuan: Untuk mendeskripsikan distribusi frekuensi efek samping pada perawatan kebidanan di Rumah Sakit Umum Daerah (RSUD) Pariaman berdasarkan metode IHI Global Trigger Tool. Metode: Penelitian ini merupakan studi kasus dengan desain penyelesaian masalah. Identifikasi instrumen insiden keselamatan pasien menggunakan alat Pemicu IHI digunakan untuk melakukan tinjauan rekam medis pasien sekunder data kebidanan RSUD Pariaman. Hasil: Ditemukan 41 (41,7\%) pasien dengan pemicu (+) jumlah pemicu 92, rata-rata 2,04 pemicu per pasien. Ditemukan $9(9,4 \%)$ pasien dengan efek samping 12 , rata-rata 1:33 efek samping per pasien. Jumlah yang terluka adalah 12 dengan proporsi cedera parah sebanyak $16,7 \%$. Karakteristik pasien yang paling banyak adalah $20-29$ tahun $(45,8 \%)$ dan umumnya terjadi dalam kasus rujukan darurat (70,8\%). Simpulan: Tidak ada hubungan antara usia dan keberadaan pemicu sementara status rujukan secara signifikan terkait dengan pemicu. Unit layanan kamar kebidanan merupakan unit pemicu yang paling umum (43,9\%), dan unit rawat inap adalah unit yang paling banyak terjadinya kejadian buruk (44,4\%). Sedangkan unit perawatan intensif adalah unit di mana pemicunya berpotensi tertinggi untuk menjadi peristiwa buruk (100\%). Hasil audit medis dalam rangka meningkatkan layanan dalam bentuk presentasi kasus salah satu pasien. Audit medis merupakan salah satu upaya untuk menemukan solusi perbaikan pelayanan kebidanan RSUD Pariaman. Kata kunci: Alat Pemicu Global IHI; efek samping (KTD); Rekam medis; Layanan Kesehatan Ibu; RSUD Pariaman
\end{abstract}

\section{Abstract}

Errors that occurred in the process of medical care potentially and can cause injury at patient that is adverse events. Institute for Healthcare Improvement Global Trigger Tool is one of the retrospective analysis method that uses the "originator" or "triggers" to detect the possibility of adverse event. The importance of hospitals in providing services and in order to improve obstetric care, then IHI can be an alternative answer the problems that exist. Objectives: To describe the distribution of the frequency of adverse events at obstetric care in Pariaman General Hospital based on IHI Global Trigger Tool methods. Methods: This research is a case study with design of problem solving. The instrument identification of patient safety incidents using IHI Trigger tool used to perform medical 
record review of secondary data obstetric patients Pariaman General Hospital. Results: Found 41 (41.7\%) patients with trigger (+) the number of trigger 92, an average of 2.04 trigger per patient. Found 9 (9.4\%) patients with adverse events 12, an average of 1:33 adverse event per patients. The number of injured was 12 with a proportion of severe injuries as much as $16.7 \%$. Patient characteristics that is most was $20-29$ years (45.8\%) and generally occur in the case of emergency referral (70.8\%). Conclusions: There is no relationship between age and the presence of the trigger while referral status was significantly associated with the trigger. Obstetrics room service unit is the unit most common trigger (43.9\%), and inpatient units are the units most widely occurrence of adverse events (44.4\%). While the intensive care unit is a unit where the triggers highest potential to be adverse event (100\%). Medical audit results in order to improve services in the form of case presentation one of the patients. Medical audit is one of the efforts to find the solution repair obstetric care Pariaman General Hospital.

Keywords: IHI Global Trigger tools; adverse events (KTD); Medical records; Maternal Health Services; Pariaman General Hospital

\section{PENDAHULUAN}

Kesalahan yang terjadi dalam proses asuhan medis ini akan mengakibatkan atau berpotensi menimbulkan cedera yang dalam praktiknya akan berupa kejadian tidak diinginkan (KTD $=$ missed $=$ Adverse event), atau hampir terjadi kejadian tidak diinginkan (near miss). Near miss ini dapat disebabkan karena keberuntungan (pasien makan obat kontra indikasi tapi tak timbul reaksi obat) atau pencegahan (pasien akan terima suatu obat dengan dosis letal, tetapi staf lain mengetahui dan membatalkannya sebelum obat diberikan). ${ }^{1}$

WHO menyebutkan 1 dari 10 pasien yang dirawat inap mengalami KTD, 1,4 juta pasien rawat inap di seluruh dunia mengalami KTD selama dirawat. Sepuluh persen KTD terjadi pada pasien rawat jalan dan akan meningkat 20 persen pada rawat inap. Sepuluh penyebab tersering akibat KTD yaitu; pneumonia, infeksi pasca operasi, ulkus disebabkan imobilisasi, sepsis, injury, phlebitis, keterlambatan diagnosis, luka pada organ tubuh lain, perdarahan akibat tindakan medis dan infeksi akibat pemasangan alat medis. ${ }^{2}$

Terdapat beberapa metode yang bisa dilakukan untuk mengidentifikasi KTD di rumah sakit yaitu: 1 ). Metode survei atau wawancara pasien (beneficiery interview), 2). Metode penyaringan (screening) data administratif (administrative data screening) termasuk metode algoritma indikator patient safety dan Identifikasi indikator POA, 3) Metode review laporan insiden rumah sakit, 4), Metode penyaringan rekam medis termasuk alat yang dikembangkan oleh Institute for Healthcare Improvement (IHI) untuk mengembangkan alat untuk identifikasi KTD yaitu IHI Global trigger tool, 5). Metode review rekam medis. ${ }^{3}$

Beberapa penelitian telah dilakukan untuk membandingkan metode IHI Global Trigger Tool dengan metode lain untuk mengidentifikasikan adanya KTD. Salah satunya adalah yang dilakukan Naessens (2009) dengan membandingkan 3 jenis 
metode untuk mengidentifikasi KTD pada Mayo Clinic Rochester Hospital yaitu metode Agency for Healthcare Research and Quality (AHRQ), Patient Safety Indicator (PSIs), metode laporan provider, serta metode IHI Global Trigger Tool (IHI GTT). Penelitian ini menyimpulkan bahwa IHI Global Trigger Tool lebih sederhana, murah, sensitif dan konsisten dalam mengidentifikasi KTD di rumah sakit. ${ }^{4}$

Kendala yang dihadapi selama ini adalah belum adanya data tentang laporan KTD di RSUD Pariaman. Namun dari hasil survei sederhana yang dilakukan peneliti pada bulan Agustus 2012, ditemukan 3 KTD dari 15 rekam medis yang diambil secara acak di bagian pelayanan kebidanan RSUD Pariaman selama periode Juni-Agustus 2012 atau sebesar $20 \%$.

Mempertimbangkan betapa pentingnya misi RSUD, Pariaman untuk mampu memberikan pelayanan kesehatan yang terbaik terhadap pasien mengharuskan rumah sakit untuk berusaha mengurangi medical error sebagai bagian dari penghargaannya terhadap kemanusiaan, maka diperlukan adanya data yang akurat tentang KTD di rumah sakit, khususnya pada pelayanan kebidanan sehingga dapat menjadi dasar dikembangkan sistem patient safety yang dirancang mampu menjawab permasalahan yang ada.

\section{METODE}

Jenis penelitian ini adalah studi kasus (case study exploratory) dengan desain pemecahan masalah (problem solving). Instrumen identifikasi insiden patient safety menggunakan IHI Trigger tool yang digunakan untuk melakukan review data sekunder rekam medis (RM) pasien kebidanan RSUD Pariaman dari bulan Februari sampai dengan Juli tahun 2012. Selanjutnya dicarikan penyelesaiannya dengan membuat analisis penyebab masalah dan mencari solusi melalui kajian kasus dengan dokter dan manajemen di RSUD Pariaman.

Populasi dan subjek penelitian adalah seluruh pasien yang pernah dirawat inap di pelayanan kebidanan RSUD Pariaman pada periode Februari sampai Juli 2012 dengan besar sampel 94 pasien.

Data kuantitatif dianalisis secara deskriptif (distribusi frekuensi) dan analisis deskriptif untuk mengetahui jumlah trigger dan KTD yang terjadi di unit pelayanan, dihitung rata-rata trigger, KTD dan rata-rata LOS. Dihitung tingkat cedera yang terjadi akibat KTD. Kejadian trigger dan KTD akan dibandingkan dengan status rujukan dan usia pasien dengan uji t-test dan Chi square test. Berdasarkan data KTD ini, salah satunya dilakukan audit medis dengan menggunakan metode pembahasan kasus (case presentation) sehingga didapatkan beberapa solusi untuk perbaikan pelayanan di pelayanan kebidanan RSUD Pariaman.

\section{HASIL DAN PEMBAHASAN}

Dari 96 rekam medis yang dilakukan analisis oleh reviewer pendamping, distribusi RM pasien mayoritas berusia 2029 tahun sebesar 44 orang $(45,8 \%)$, sedangkan terkecil berusia kurang dari 20 
tahun sebanyak 3 orang (9\%). Pasien dengan trigger $(+)$ terbesar terjadi pada kelompok usia 30-39 tahun 19 orang (50\%) dan trigger (-) terkecil ditemukan pada usia kecil 20 tahun 1 orang (33,3\%). Hasil analisis statistik $(\alpha=0,05$ dan $95 \% \mathrm{Cl}$ ) menyimpulkan tidak terdapat hubungan antara kelompok usia dengan adanya trigger yang ditemukan $(p=>0,30$ dan $\mathrm{RR}=0,77$ ).
Tabel 1. Karakteristik responden penelitian ( $\mathrm{n}=96)$

\begin{tabular}{lcc}
\hline \multicolumn{1}{c}{ Karakteristik } & Jumlah & $\begin{array}{c}\text { Persentase } \\
(\%)\end{array}$ \\
\hline Usia (tahun) & 3 & 9 \\
$<20$ & 44 & 45,9 \\
$20-29$ & 38 & 39,6 \\
$30-39$ & 11 & 11,5 \\
$>40$ & & \\
Rujukan & 68 & 70,8 \\
Emergensi & 28 & 29,2 \\
Non-emergensi & 96 & 100,0 \\
Jumlah & \\
\hline
\end{tabular}

Tabel 2. Distribusi trigger menurut karakteristik

\begin{tabular}{lccccc}
\hline Usia (tahun) & $\mathrm{n}(\%)$ & $\begin{array}{c}\text { Trigger }(+) \\
\mathrm{n}(\%)\end{array}$ & $\begin{array}{c}\text { Trigger }(-) \\
\mathrm{n}(\%)\end{array}$ & p-value/RR & $\begin{array}{c}95 \% \mathrm{Cl} \\
\text { (lower-upper) }\end{array}$ \\
\hline$<20$ & $3(3,1)$ & $1(33,3)$ & $2(66,7)$ & $0,30 / 0,70$ & $0,473-1,260$ \\
$20-29$ & $44(45,8)$ & $17(38,6)$ & $27(61,4)$ & & \\
$30-39$ & $38(39,6)$ & $19(50,0)$ & $19(50,0)$ & & \\
$>40$ & $11(11,5)$ & $4(36,4)$ & $7(63,6)$ & & \\
Rujukan & & & & & \\
Emergensi & $68(70,8)$ & $34(50,0)$ & $34(50,0)$ & $0,02 / 2,00$ & $1,009 / 3,964$ \\
Non- & $28(29,2)$ & $7(25,0)$ & $21(75,0)$ & & \\
emergensi & & & & & \\
Jumlah & $96(100)$ & $41(42,7)$ & $55(57,3)$ & & \\
\hline
\end{tabular}

Trigger, KTD dan Cedera di Pelayanan Kebidanan RSUD Pariaman

Tabel 3. Trigger (+), KTD (+), dan jenis cedera serta LOS KTD di pelayanan kebidanan RSUD Pariaman

\begin{tabular}{lcc}
\hline Kriteria & Jumlah & Keterangan \\
\hline Responden & 41 & $\mathrm{n}=96$ \\
dengan trigger $(+)$ & $(41,7 \%)$ & \\
Jumlah trigger & 92 & $\mathrm{n}=96$ \\
& (rerata & \\
& $2,04)$ & \\
Responden & 9 & \\
dengan KTD $(+)$ & $(9,4 \%)$ \\
Jumlah KTD & 12 & \\
& $($ rerata & \\
Jumlah cedera & $1,33)$ & \\
Cedera ringan & 12 & \\
& 10 & $\mathrm{E}$ dan F \\
& $(10,4 \%)$ &
\end{tabular}

\begin{tabular}{lcc} 
Cedera berat & 2 & I dan H \\
& $(2,08 \%)$ & \\
$\begin{array}{l}\text { Total Length of } \\
\text { Stay (LOS) }\end{array}$ & 71 hari & \\
\hline
\end{tabular}

Berdasarkan tabel 3 maka dapat dihitung insiden KTD per 1000 pasien per hari yaitu dengan membagi jumlah KTD dengan total LOS dikalikan 1000 maka didapatkan angka 12/71×1000 sama dengan $169 \mathrm{KTD} / 1000$ pasien/hari. Ukuran lain adalah insiden KTD per 100 pasien yaitu dengan membagi jumlah KTD dengan jumlah pasien yang direview dikalikan 100, maka didapat angka $12 / 96 \times 100$ sama dengan $12,5 \mathrm{KTD} / 100$ pasien $=12,5 \%$. 
Tabel 4. Distribusi KTD dan cedera pada pelayanan kebidanan

\begin{tabular}{ccllccc}
\hline No & $\begin{array}{r}\text { Nama } \\
\text { Pasien }\end{array}$ & Unit Pelayanan & \multicolumn{1}{c}{ Kode Triggers } & LOS & KTD & Cedera \\
\hline 1 & P14 & ICU & C1, C13, I2, P4, P7 & 1 & + & I dan H \\
2 & P22 & Rawat Inap & C6, C13, P4 & 1 & - & - \\
3 & P36 & Rawat Inap & C1, C6, C10, P5 & 7 & + & E \\
4 & P47 & Rawat Inap & C1, C6 & 6 & + & F \\
5 & P51 & Medikasi & C1, C6, M6 & 6 & + & E \\
6 & P61 & Rawat Inap & C10, C11 & 3 & + & E \\
7 & P66 & Rawat Inap & C1, C6 & 13 & + & F \\
8 & P78 & Kamar Bersalin & C1, C6, M6, P4,P6 & 9 & + & E \\
9 & P82 & OK & C9, C11, S1 & 19 & + & E dan F \\
10 & P83 & Kamar Bersalin & C1, C6, P4, P2, P6 & 6 & + & E dan F \\
\hline & & Jumlah & & 71 & 9 & 12 \\
\hline
\end{tabular}

Keterangan:

I: Pasien mengalami cedera yang berakibat pasien meninggal; $\mathrm{H}$ : Pasien mengalami cedera menetap dan memerlukan intervensi untuk mempertahankan hidupnya; E: Pasien mengalami cedera sementara dan tidak memerlukan intervensi; $F$ : Pasien mengalami cedera sementara dan memerlukan perawatan awal dan lanjutan

Trigger, KTD dan Cedera di Ruangan Rawat Inap

Tabel 5. Trigger (+), KTD (+) dan jenis cedera serta LOS KTD di Ruangan Rawat Inap RSUD Pariaman

\begin{tabular}{lcc}
\hline Kriteria & Jumlah & Keterangan \\
\hline Responden & 14 & $\mathrm{n}=96$ \\
dengan trigger $(+)$ & $(15,2 \%)$ & \\
Jumlah trigger & 34 & $\mathrm{n}=96$ \\
& (rerata & \\
& $2,42)$ & \\
Responden & 4 & \\
dengan KTD $(+)$ & $(4,17 \%)$ & \\
Potensi trigger & 4 (rerata & \\
menjadi KTD & $1)$ & \\
Jumlah cedera & 4 & \\
Cedera ringan & 4 & $\mathrm{E}$ dan F \\
& $(100,0 \%)$ & \\
Cedera berat & $0(0 \%)$ & I dan H \\
Total Length of & 29 hari & \\
Stay (LOS) & & \\
\hline
\end{tabular}

Berdasarkan tabel 5 maka untuk ruangan rawat inap kebidanan RSUD Pariaman dapat dihitung insiden KTD per 1000 pasien per hari yaitu dengan membagi jumlah KTD dengan total LOS dikalikan 1000 maka didapatkan angka 4/29×1000 sama dengan 137 KTD/1000 pasien/hari. Sementara Potensi trigger menjadi adalah sebesar $28,6 \%$.

Trigger, KTD dan Cedera di Ruangan Pelayanan Medikasi

Berdasarkan tabel 6, maka untuk ruangan pelayanan medikasi kebidanan RSUD Pariaman dapat dihitung insiden KTD per 1000 pasien per hari yaitu dengan membagi jumlah KTD dengan total LOS dikalikan 1000 maka didapatkan angka 1/6×1000 sama dengan 166 KTD/1000 pasien/hari. Dan potensi trigger menjadi KTD adalah sebesar $16,7 \%$. 
Tabel 6. Trigger (+), KTD (+) dan jenis cedera serta LOS KTD di Ruangan Pelayanan Medikasi RSUD Pariaman

\begin{tabular}{lcc}
\hline Kriteria & Jumlah & Keterangan \\
\hline Responden & 6 & $\mathrm{n}=96$ \\
dengan trigger $(+)$ & $(6,25 \%)$ & \\
Jumlah trigger & 12 & $\mathrm{n}=96$ \\
& $\begin{array}{c}\text { (rerata } \\
\text { Re }\end{array}$ & \\
Responden & 1 & \\
dengan KTD (+) & $(1,04 \%)$ \\
Jumlah KTD & 1 (rerata \\
\multicolumn{4}{c}{$1)$} \\
Potensi trigger & $16,7 \%$ \\
menjadi KTD & & \\
Jumlah cedera & 1 & \\
Cedera ringan & 1 & $\mathrm{E}$ \\
Cedera berat & $(100,0 \%)$ \\
Total Length of & $0(0 \%)$ \\
Stay (LOS) & 6 hari \\
\hline
\end{tabular}

Trigger, KTD dan Cedera di Ruangan Kamar Operasi

Tabel 7. Trigger (+), KTD (+) dan jenis cedera serta LOS KTD di Ruangan Kamar Operasi RSUD Pariaman

\begin{tabular}{|c|c|c|}
\hline Kriteria & Jumlah & Keterangan \\
\hline $\begin{array}{l}\text { Responden } \\
\text { dengan trigger (+) }\end{array}$ & $\begin{array}{c}2 \\
(2,08 \%)\end{array}$ & $\mathrm{n}=96$ \\
\hline Jumlah trigger & $\begin{array}{c}3 \text { (rerata } \\
1,5)\end{array}$ & $n=96$ \\
\hline $\begin{array}{l}\text { Responden } \\
\text { dengan KTD (+) }\end{array}$ & $\begin{array}{c}1 \\
(1,04 \%)\end{array}$ & \\
\hline Jumlah KTD & $\begin{array}{l}2 \text { (rerata } \\
2 \text { ) }\end{array}$ & \\
\hline $\begin{array}{l}\text { Potensi trigger } \\
\text { menjadi KTD }\end{array}$ & $50 \%$ & $1 / 2 \times 100 \%$ \\
\hline Jumlah cedera & 2 & \\
\hline Cedera ringan & $\begin{array}{c}2 \\
(100,0 \%)\end{array}$ & $E$ dan $F$ \\
\hline Cedera berat & $0(0 \%)$ & \\
\hline $\begin{array}{l}\text { Total Length of } \\
\text { Stay (LOS) }\end{array}$ & 19 hari & \\
\hline
\end{tabular}

Berdasarkan tabel 7 maka untuk ruangan pelayanan kamar operasi kebidanan RSUD
Pariaman dapat dihitung insiden KTD per 1000 pasien per hari yaitu dengan membagi jumlah KTD dengan total LOS dikalikan 1000 maka didapatkan angka 1/19×1000 sama dengan 52,6 KTD/1000 pasien/hari. Dan potensi trigger menjadi KTD adalah sebesar $50 \%$.

\section{Trigger, KTD dan Cedera di Ruangan ICU RSUD Pariaman}

Tabel 8. Trigger (+), KTD (+) dan jenis cedera serta LOS KTD di Ruangan ICU RSUD Pariaman

\begin{tabular}{|c|c|c|}
\hline Kriteria & Jumlah & Keterangan \\
\hline $\begin{array}{l}\text { Responden } \\
\text { dengan trigger (+) }\end{array}$ & $\begin{array}{c}1 \\
(1,04 \%)\end{array}$ & $n=96$ \\
\hline Jumlah trigger & $\begin{array}{l}1 \text { (rerata } \\
1 \text { ) }\end{array}$ & $n=96$ \\
\hline $\begin{array}{l}\text { Responden } \\
\text { dengan KTD (+) }\end{array}$ & $\begin{array}{c}1 \\
(1,04 \%)\end{array}$ & \\
\hline Jumlah KTD & $\begin{array}{l}2 \text { (rerata } \\
2 \text { ) }\end{array}$ & \\
\hline $\begin{array}{l}\text { Potensi trigger } \\
\text { menjadi KTD }\end{array}$ & $100 \%$ & $1 / 1 \times 100 \%$ \\
\hline Jumlah cedera & 2 & \\
\hline Cedera ringan & $0(0 \%)$ & I dan $\mathrm{H}$ \\
\hline Cedera berat & $\begin{array}{c}2 \\
(100,0 \%)\end{array}$ & \\
\hline $\begin{array}{l}\text { Total Length of } \\
\text { Stay (LOS) }\end{array}$ & 1 hari & \\
\hline
\end{tabular}

Berdasarkan tabel 8 maka untuk ruangan pelayanan kamar operasi kebidanan RSUD Pariaman dapat dihitung insiden KTD per 1000 pasien per hari yaitu dengan membagi jumlah KTD dengan total LOS dikalikan 1000 maka didapatkan angka 1/1×1000 sama dengan $1000 \mathrm{KTD} / 1000$ pasien/hari. Dan potensi trigger menjadi KTD adalah sebesar $100 \%$.

\section{Trigger, KTD dan Cedera di Kamar Bersalin RSUD Pariaman}

Berdasarkan tabel 9 maka untuk ruangan pelayanan kamar operasi kebidanan RSUD 
Pariaman dapat dihitung insiden KTD per 1000 pasien per hari yaitu dengan membagi jumlah KTD dengan total LOS dikalikan 1000 maka didapatkan angka 3/15×1000 sama dengan $200 \mathrm{KTD} / 1000$ pasien/hari. Dan potensi trigger menjadi KTD adalah sebesar $100 \%$.

Tabel 9. Trigger (+), KTD (+) dan jenis cedera serta LOS KTD di Kamar Bersalin RSUD Pariaman

\begin{tabular}{lcc}
\hline Kriteria & Jumlah & Keterangan \\
\hline Responden & 18 & $\mathrm{n}=96$ \\
dengan trigger $(+)$ & $(18,8 \%)$ & \\
Jumlah trigger & 42 & $\mathrm{n}=96$ \\
& $\begin{array}{c}\text { (rerata } \\
\text { Responden }\end{array}$ & $2,3)$ \\
dengan KTD $(+)$ & $(2,08 \%)$ \\
Jumlah KTD & $3($ rerata \\
\multicolumn{4}{c}{$1,5)$} \\
Potensi trigger & $11,1 \%$ & $2 / 18 \times 100 \%$ \\
menjadi KTD & & \\
Jumlah cedera & 3 & \\
Cedera ringan & 3 & $\mathrm{E} \mathrm{dan} \mathrm{F}$ \\
\multicolumn{4}{c}{$(100,0 \%)$} \\
Cedera berat & $0(0 \%)$ \\
Total Length of & 15 hari \\
Stay (LOS) & & \\
\hline
\end{tabular}

Upaya Perbaikan Pelayanan Kebidanan RSUD Pariaman

Dalam upaya perbaikan pelayanan kebidanan, maka telah dilakukan audit medis dalam bentuk pembahasan kasus (case presentation) salah satu KTD yang telah diidentifikasi. Kasus yang dipilih adalah pasien dengan kode P14 yang meninggal di unit pelayanan ICU. Kegiatan presentasi kasus ini dilakukan pada tanggal 15 Juli 2013 dengan topik presentasi kasus kematian di pelayanan kebidanan dan dihadiri 15 peserta dari staf medik dan manajemen.
Diskusi / Kesimpulan pertemuan itu adalah: (1) Presentasi kasus kali ini membahas kematian ibu di pelayanan kebidanan; (2) Penyebab kematian overload pemberian cairan pada pasien hipertensi dalam kehamilan sehingga beban kerja jantung yang berlebihan berakibat henti jantung (cardiac arrest); (3) Terdapat pelanggaran standar pelayanan minimal (SPM), karena tidak seharusnya pasien dipindahkan ke ruangan kamar bersalin dari ICU pada pasien eklampsia sekalipun hemodinamiknya stabil; (4) Kurangnya alat monitor di ruang kamar bersalin dan ICU; (5) Akibat tidak adanya dokter ruangan yang ikut membantu monitoring dan penanganan cepat kasus emergensi sehingga penanganan jadi lambat; (6) Semua pasien eklampsia harus dirawat di ICU sehingga 24 jam post-partum dan keadaan umum baik; (7) Semua dokter harus mematuhi standar pelayanan minimal SPM; (8) Tidak adanya pemantauan yang baik selama di kamar bersalin akibat tenaga bidan masih kurang.

Sedangkan beberapa saran-saran yang didapatkan adalah sebagai berikut: (1) Perbaiki koordinasi antara ruangan ICU, kamar bersalin, dan dokter jaga; (2) Mengajukan penambahan dokter ruangan, hal ini berarti ada penambahan dokter baru lagi; (3)Mengajukan penambahan alat seperti monitor untuk ruangan kamar bersalin; 4() Mengajukan kesiapan laboratorium 24 jam; (5) Sosialisasi kembali standar pelayanan minimal (SPM) pelayanan kebidanan kepada seluruh petugas termasuk dokter jaga; (6) Setiap 
dokter harus kembali memperhatikan standar pelayanan medis.

\section{SIMPULAN}

Ditemukan pasien dengan trigger (+) sebanyak 41 pasien $(41,7 \%)$ dengan Jumlah trigger 92 dan rata-rata 2,04 trigger per pasien di Pelayanan Kebidanan RSUD Pariaman.

Ditemukan pasien dengan KTD (+) sebanyak 9 pasien $(9,4 \%)$ dengan jumlah KTD 12 dan rata-rata 1,33 KTD per pasien di Pelayanan Kebidanan RSUD Pariaman.

Ditemukan Jumlah cedera (harm) sebanyak 12 dengan proporsi cedera berat sebanyak $16,7 \%$.

Insiden KTD di RSUD Pariaman adalah 169 KTD/1000 pasien/hari atau setara dengan $12,5 \%$ KTD/100 pasien.

Insiden KTD di ruangan rawat inap RSUD Pariaman adalah 137 KTD/1000 pasien/hari dengan potensi trigger menjadi KTD sebesar 28,65.

Insiden KTD di Pelayanan medikasi RSUD Pariaman adalah 166 KTD/1000 pasien/hari dan potensi trigger menjadi KTD adalah sebesar $16,7 \%$.

Insiden KTD di Pelayanan Kamar operasi RSUD Pariaman adalah 52,6 KTD/1000 pasien/hari dan potensi trigger menjadi KTD adalah sebesar $50 \%$.

Insiden KTD di Pelayanan ruangan ICU RSUD Pariaman adalah 1000 KTD/1000 pasien/hari dan potensi trigger menjadi KTD adalah sebesar $100 \%$.

Insiden KTD di Pelayanan Kamar bersalin RSUD Pariaman adalah 200 KTD/1000 pasien/hari dan potensi trigger menjadi KTD adalah sebesar $11,1 \%$.

Ditemukan jenis cedera dengan kategori $\mathrm{E}$ (50\%), Kategori $\mathrm{F}(33,3 \%$, Kategori $\mathrm{H}(8,3 \%)$ dan kategori I (8,3\%), Tak ditemukan jenis cedera kategori $\mathrm{G}$.

Telah dilakukan audit medis pada salah satu kasus KTD yang ditemukan untuk mencari solusi perbaikan.

Solusi perbaikan dapat membantu perbaikan pelayanan kebidanan di RSUD Pariaman.

\section{DAFTAR PUSTAKA}

1. Institude of Medicine, IOM. Total quality management for adverse event. Edisi Pertama. Jakarta: PT. Gramedia; 2000.

2. World Health Organization. IBEAS: a pioneer study on patient safety in Latin America. Geneva: World Health Organization; 2011.

3. Office of Inspector General. Adverse Events In Hospitals: Overview of Key Issues. Washington DC: Department of Health and Human Services; 2008.

4. Naessens JM, Campbell CR, Huddleston JM, Berg BP, Lefante JJ, Williams AR, et al. A comparison of hospital adverse events identified by three widely used detection methods. Int J Qual Health Care. 2009; 21(4):301-7. 